\title{
Capítulo 5 - Testando a relação em outros dados
}

\author{
Ivan Filipe de Almeida Lopes Fernandes
}

\section{SciELO Books / SciELO Livros / SciELO Libros}

FERNANDES, I.F.A.L. Testando a relação em outros dados. In: A democracia reduz a desigualdade econômica? Um estudo sobre as possibilidades de construção de uma sociedade mais igual por meio da democracia [online]. São Bernardo do Campo, SP: Editora UFABC, 2017, pp. 223-256. ISBN: $978-$ 85-68576-79-3. https://doi.org/10.7476/9788568576793.0006.

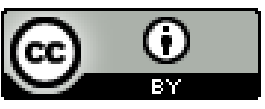

All the contents of this work, except where otherwise noted, is licensed under a Creative Commons Attribution 4.0 International license.

Todo o conteúdo deste trabalho, exceto quando houver ressalva, é publicado sob a licença Creative Commons Atribição 4.0.

Todo el contenido de esta obra, excepto donde se indique lo contrario, está bajo licencia de la licencia $\underline{\text { Creative }}$ Commons Reconocimento 4.0. 


\section{Capítulo 5}

\section{Testando a relação em outros dados}

O objetivo principal deste quinto capítulo é aprofundar a consistência dos achados anteriormente apresentados e tornar mais latente a veracidade da hipótese de que os efeitos da democracia sobre a desigualdade são heterogêneos e de que a democracia é um contundente agente redutor da desigualdade econômica em sociedades mais desiguais. Para tal empreitada o dividimos em quatro seções.

Nas duas primeiras analisamos outras mensurações de desigualdade e democracia para o período pós $2^{\text {a }}$ Guerra Mundial. Na primeira analisamos se os resultados permanecem se mudarmos a medida de democracia para a escala elaborada pelo POLITY IV. Na segunda analisamos as três outras medidas de desigualdade propostas no capítulo 3, SWIID, SIID e Capshares. Na terceira seção analisamos a relação da democracia e desigualdade em um horizonte histórico mais extenso, utilizando dados que mensuram as duas variáveis desde o século XIX.

Na quarta seção verificamos se os efeitos da democracia são localizados no tempo ou se estendem ao longo da experiência democrática, tal como alguns autores como Muller (1988) e Sirowy e Inkeles (1990) entendem que po- 
dem funcionar os mecanismos causais da democracia sobre a desigualdade. Para tal discussão fazemos uma pequena alteração na variável independente. A medida deixa de ser se um simples indicador se o país possui um regime democrático ou não e passa a ser uma medida da persistência do regime, calculada por meio da contagem de anos passados desde a transição democrática.

\subsection{Polity IV}

Conforme exposto no capítulo 3, existe um debate sobre como o fenômeno da democracia deve ser mensurado empiricamente e em quais dimensões de um regime político estão suas propriedades essenciais. Optamos como medida principal a proposta dicotômica de Cheibub, Gandhi e Vreeland (2010). Entretanto, existem outras duas medidas de regime político usualmente utilizadas na literatura e entre elas destacamos o projeto do POLITY IV que mensura diversas características dos regimes políticos (MARSHALL et al., 2002).

No próprio capítulo 3, após apresentarmos brevemente o formato policotômico da medida do POLITY IV, propusemos três novas formas de mensuração da competição política de um determinado país baseadas em duas escalas do POLITY IV: a) Participação: classificação dicotômica na qual os regimes políticos são qualificados como tendo participação política competitiva (democráticos) ou não competitiva (autoritários); b) Recrutamento: classificação dicotômica na qual o método de recrutamento eleitoral dos chefes do Executivo é considerado como democrático e todos os outros são considerados como autoritários; e, por fim, c) Competição: a interação entre 
as duas variáveis, sendo considerados democráticos apenas os regimes com participação política competitiva e recrutamento do Executivo pela via eleitoral.

Embora aparentemente a variável do CGV e estas transformações das variáveis do POLITY mensurem uma mesma dimensão do fenômeno político democrático, as correlações entre as três medidas não são tão elevadas quanto o esperado. A correlação entre Participação e o CGV é de apenas 0.58. Dos 6418 regimes analisados pelas duas escalas concomitantemente, em 38 casos a classificação POLITY IV analisa a participação como competitiva e CGV define o regime como ditatorial. E 1351 casos analisados como democráticos pelo CGV são considerados como regimes cuja participação não é competitiva pelo POLITY IV. Fica claro que a variável natureza competitiva da participação política do POLITY IV é mais conservadora e exigente que a definição minimalista assumida pelo CGV.

Já a correlação entre Recrutamento e o CGV é maior, próxima de 0.79. Dos 6418 casos analisados concomitantemente existe desacordo em 663. Destes, 232 são classificados como ditaduras pelo CGV e como recrutamento eleitoral pelo POLITY IV e 431 democracias do CGV não possuem um critério de recrutamento considerado como eleitoral pelo POLITY IV. Por fim, a nova medida de Competição que utiliza os dois requisitos acima se aproxima muito da variável Participação, pois apenas em 8 casos o POLITY IV classificou um mesmo caso como tendo participação política competitiva e método de recrutamento do Executivo não eleitoral ${ }^{109}$. Posto

\footnotetext{
109 Taiwan (1992 a 1995) e Uruguai (1985 a 1988). O primeiro é classificado como ditadura pelo CGV e o segundo como democracia. A correlação entre as variáveis Participação e Competição é de 0.996.
} 
isto, devido a esta enorme convergência entre Participação e Competição, testaremos a hipótese dos efeitos heterogêneos apenas para a segunda, que é justamente a que agrega as duas medidas de Participação e Recrutamento.

Tabela 13 - Estatística descritiva dos dados de participação e recrutamento

\begin{tabular}{|c|c|c|c|}
\hline \multicolumn{4}{|c|}{1 - Correlações (1963 - 2008) } \\
\hline & CGV & Participação & Recrutamento \\
\hline Participação & 0.578 & & \\
\hline Recrutamento & 0.785 & 0.642 & \\
\hline Competição & 0.579 & 0.996 & 0.646 \\
\hline \multicolumn{4}{|c|}{2 - Tabelas de Contingência: POLITY e CGV (1963 - 2008) } \\
\hline $\mathrm{CGV}=0$ & & Recrutamento & \\
\hline Participação & 0 & 1 & Total \\
\hline 0 & 3572 & 198 & 3770 \\
\hline 1 & 4 & 34 & 38 \\
\hline Total & 3576 & 232 & 3808 \\
\hline $\mathrm{CGV}=1$ & & Recrutamento & \\
\hline Participação & 0 & 1 & Total \\
\hline 0 & 427 & 924 & 1351 \\
\hline 1 & 4 & 1255 & 1259 \\
\hline \multirow[t]{2}{*}{ Total } & 431 & 2179 & 2610 \\
\hline & & CGV & \\
\hline Competição & 0 & 1 & Total \\
\hline 0 & 3774 & 1355 & 5129 \\
\hline 1 & 34 & 1255 & 1289 \\
\hline Total & 3808 & 2610 & 6418 \\
\hline
\end{tabular}

Observação: A diferença do total desta tabela (6418) para o total da Tabela 12 (7617) decorre do fato que o Polity IV cria mais valores faltantes do que o CGV. 
Na Tabela 13 apresentamos a descrição de cada uma dessas três novas variáveis. E mostramos como elas estão fortemente relacionadas entre si e são uma definição mais conservadora do que seja um regime político democrático do que o CGV. Podemos observar nesta tabela que o CGV categoriza 3808 casos como ditaduras e 2610 como democracias. Enquanto isso, a variável Recrutamento observa 2411 (2179 + 232) casos de democracia e $4007(3576+431)$ de ditaduras. Já a variável Participação observa apenas 1297 (1259 + 38) países-anos democráticos e $5121(3770+1351)$ ditatoriais. Por fim, a variável mais restritiva, Competição, observa 1289 anos democráticos e 5129 anos ditatoriais.
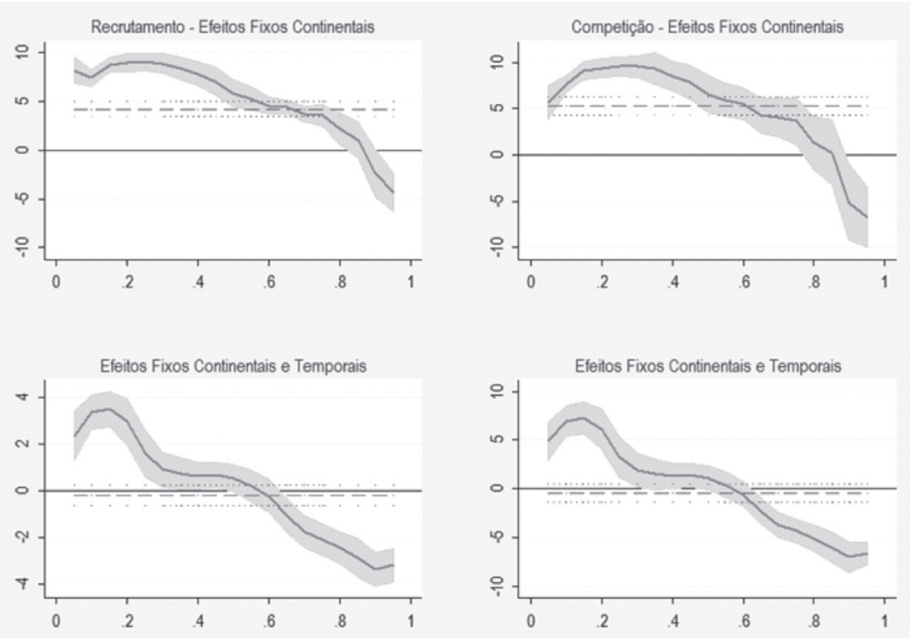

Figura 3 - Efeitos heterogêneos da democracia sobre a desigualdade econômica - POLITY IV ${ }^{110}$ Fonte: POLITY IV e UTIP-EHII

\footnotetext{
${ }^{110}$ Os modelos que mensuram democracia com a variável recrutamento tem como instrumentos de identificação difmundo, difregião, llong e horiental quando a especificação contém apenas efeitos fixos e quando são adicionadas as dummies de anos apenas difmundo identifica o modelo. Já na mensuração
} 
Discutido o formato das 3 novas variáveis, na Figura 3 apresentamos os efeitos da democracia sobre a desigualdade ao longo da distribuição da variável dependente. Como método de identificação, utilizamos os dois conjuntos de instrumentos de difusão e de longitude. Mais uma vez, incluímos dentre os cinco apenas aqueles que atendem aos critérios necessários para a validade da estimação por variável instrumental. A especificação básica dos modelos da metade superior da figura tem efeitos fixos continentais. Já a especificação da metade inferior apresenta efeitos fixos continentais e temporais. Para cada um dos modelos fizemos os testes para escolher o melhor rol de variáveis instrumentais para a identificação de democracia. Na coluna da esquerda testamos a hipótese dos efeitos heterogêneos para a variável Recrutamento. E na coluna da direita a variável mais conservadora de Competição.

O padrão da Figura 3, mais uma vez, é bem semelhante ao formato das curvas encontradas nos modelos apresentados no capítulo anterior. Encontramos um efeito positivo e homogêneo no início da distribuição de desigualdade, que vai do $1^{\circ}$ ao $4^{\circ}$ decil nas especificações que apenas contam com efeitos fixos continentais e do $1^{\circ}$ e $2^{\circ}$ decil nas especificações com efeitos fixos continentais e dummies de ano. Após este primeiro estágio, os efeitos positivos da democracia passam a ser amenizados e próximo ao $8^{\circ}$ decil nos dois primeiros modelos ou próximo ao $6^{\circ}$ decil nos dois modelos inferiores os efeitos da democracia tornam-se negativos. Em todos os modelos o efeito mais contundente e negativo da democracia em relação à desigualdade econômica é encontrado entre o $9^{\circ}$ decil e o $95^{\circ}$ centil da distribuição. Os resultados são basicamente os

de democracia pela variável competição, no modelo com apenas efeitos fixos continentais os instrumentos são difcont e difregião e após a adição de dummies de ano apenas difmundo identifica a variável endógena. 
mesmos dos encontrados anteriormente, não importando, assim, a medida de democracia utilizada.

Um último aspecto importante de ser destacado decorre do fato que apenas observando os resultados destes quatro modelos fica clara a inconsistência da análise dos efeitos da democracia por meio da estimação dos seus efeitos médios por MQO. Enquanto nos modelos com efeitos fixos continentais a democracia tem um efeito médio positivo, nos modelos que incluem efeitos fixos para os anos, as democracias passam a ter um efeito nulo. Fica patente, outra vez, a conclusão que o suposto sobre os efeitos homogêneos da democracia é sobremaneira equivocado e uma das razões que dificultam o avanço da literatura.

Por fim, testamos os mesmos modelos incorporando efeitos fixos regionais e efeitos fixos regionais e choques temporais. Os resultados são semelhantes aos encontrados até aqui, ainda que para o modelo com efeitos fixos regionais e democracia mensurada pela variável competição não tenha sido encontrado nenhuma variável instrumental que torne a estimação válida.

\subsection{Outras medidas de desigualdade}

Do mesmo modo que existe um vigoroso debate sobre como o fenômeno da democracia deve ser mensurado empiricamente, também discutimos as divergências da literatura sobre quais são as melhores formas de medir a desigualdade econômica. Apresentamos três diferentes medidas de desigualdade econômica que possuem dados disponíveis para um longo período de anos e para muitos países. As duas primeiras são o Standardized Income Inequality Data (SIID) e a Standardized World Income Inequality Database (SWIID), que mensuram o mesmo conceito tratado pelo EHII: o 
coeficiente de GINI. E a terceira, Capital Shares, captura o quanto os recursos de um determinado país são controlados pelos detentores do capital.

Esperamos encontrar relações semelhantes para diferentes mensurações do GINI, uma vez que o conceito é o mesmo: a curva de Lorenz; e a fonte primária dos dados é a compilação de surveys de GINI feita pelo UNU-WIDER. Por sua vez, em relação à terceira medida, que foi utilizada por Houle (2009) para analisar a relação entre desigualdade e processos de democratização, as expectativas são mais incertas. A variável captura outro aspecto da desigualdade: a divisão de recursos entre os detentores do capital e o resto da sociedade e não apenas a desigualdade no fluxo de renda entre os indivíduos. E a relação negativa entre democracia e desigualdade encontrada na cauda direita da distribuição de desigualdade medida pelo coeficiente de GINI não necessariamente significa, por exemplo, que os recursos utilizados pelo governo democrático para reduzir a desigualdade de renda sejam extraídos do capital. É bem possível que outros grupos da sociedade arquem com os custos de projetos e políticas públicas que almejem reduzir a desigualdade econômica.

Na Figura 4 apresentamos os efeitos da democracia, novamente mensurada pelo CGV, sobre a desigualdade econômica mensurada pelo SIID. Mais uma vez repetimos o mesmo método de identificação de democracia, utilizando os mesmos testes para identificação e verificação da hipótese de restrição de exclusão. Nesta análise temos três divergências em relação aos outros achados. Como a amostra de países analisadas pelo SIID é menos abrangente que as amostras de EHII e do SWIID $^{111}$, os primeiros passos das equações apresentaram resultados um pouco distintos. Para os dados de SIID, nenhum

\footnotetext{
111 Enquanto o EHII possui 4138 países-anos com atribuição de valores para desigualdade e democracia, o SWIID possui mais de 4700 países-anos e o SIID apenas 2302 - menos que a metade que o SWIID.
} 
instrumento é adequado para identificar corretamente as especificações sem nenhum efeito fixo e com apenas efeito fixo continental, enquanto tal identificação foi possível nos modelos de EHII e de SWIID. Além disso, apenas para os dados de SIID conseguimos estimar adequadamente a especificação de efeitos fixos regionais, enquanto o contrário aconteceu nas estimações de EHII e SWIID. Assim, para SIID temos poder estatístico para identificar as especificações com efeitos fixos continentais e temporais e as duas com efeitos fixos regionais (com e sem dummies de ano).
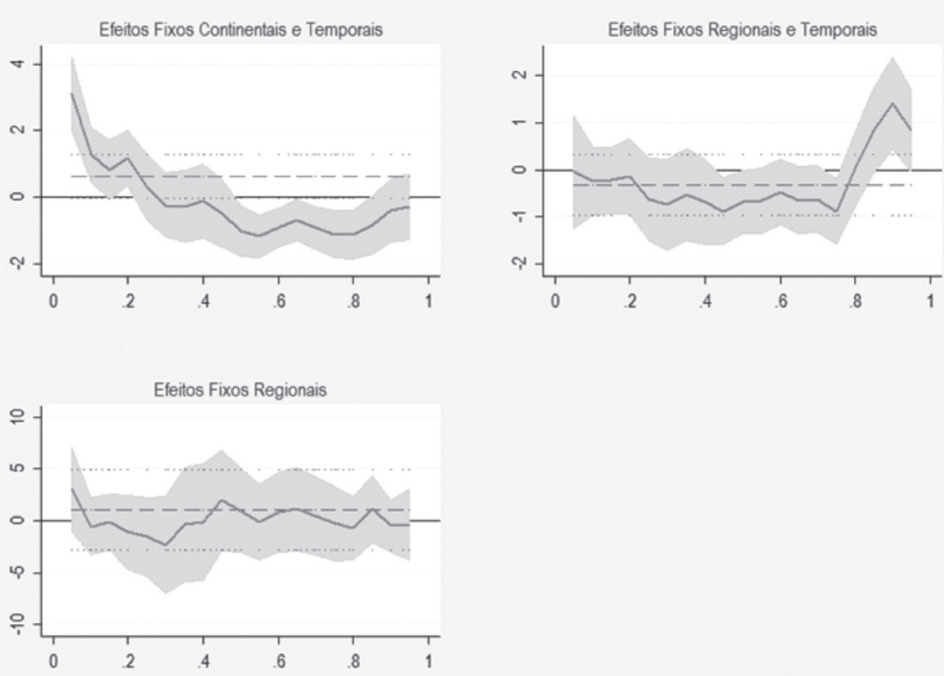

Figura 4 - Efeitos heterogêneos da democracia sobre a desigualdade econômica - Standardized Income Inequality Data (SIID) ${ }^{112}$ Fonte: CGV e SIID

112 O modelo com efeitos fixos continentais e temporais foi identificado pelos instrumentos difmundo, difcont, horiental e llong. Já o modelo com efeitos fixos regionais foi identificado por difmundo e o modelo com efeitos fixos regionais e temporais foi identificado por difmundo, difcont, horiental e llong. 
Os gráficos da Figura 4 apresentam um cenário completamente diferente do encontrado até agora. Em dois dos três gráficos parece que o suposto da homogeneidade dos efeitos da democracia sobre a desigualdade encontra respaldo empírico. Além de serem homogêneos, também é indicado que os efeitos da democracia sobre a desigualdade são nulos, pois as duas curvas - a de efeitos heterogêneos e de efeitos homogêneos - contêm em seus respectivos intervalos de confiança o eixo de referência dos efeitos nulos.

$\mathrm{Na}$ especificação com efeito fixo regional esse resultado é claríssimo. Em todos os decis da distribuição de desigualdade, a curva de efeitos heterogêneos está contida dentro do intervalo de confiança da reta de efeitos homogêneos, enquanto ambas incluem dentro de seus intervalos de confiança o eixo de efeitos nulos. O mesmo acontece na especificação com efeitos fixos regionais e temporais, com exceção apenas do último decil, onde há um efeito positivo da democracia na desigualdade. Em todos os outros decis, do 0.1 ao 0.8 , o efeito é homogêneo e nulo. Por fim, na especificação com efeitos fixos continentais e temporais, os resultados recuperam, ainda que de maneira tímida, o aspecto encontrado anteriormente. Há um efeito positivo da democracia sobre a desigualdade nas sociedades mais iguais e a partir do $4^{\circ}$ decil este efeito é negativo, embora seja relativamente homogêneo até o $95^{\circ}$ centil.

A partir dos dados exposto nos gráficos acima, duas possibilidades empíricas emergem para explicar as brutais diferenças encontradas. Como os dados de desigualdade do SIID abrangem um menor conjunto de países, é possível que as discrepâncias sejam resultados não das diferentes técnicas de mensuração de Babones e Alvarez-Rivadulla (2007), mas 
sim meramente uma questão amostral ${ }^{113}$. Para isso, realizamos dois exercícios: re-estimamos os resultados anteriores de EHII apenas com os casos para os quais o SIID tem dados e em segundo lugar avaliamos um terceiro banco de dados, o SWIID, que possui mais informações e cuja técnica de estimação é semelhante às adotadas por Babones e Alvarez-Rivadulla (2007).

Para utilizarmos os dados de EHII nos mesmos casos de SIID, optamos por não avaliar o primeiro passo da equação e aceitar os instrumentos que identificaram democracia nos 3 modelos da Figura 4. O total de dados analisados nesta estimação é menor, pois não há dados de EHII em 396 países-anos para os quais as informações de SIID estão disponíveis. O resultado que emerge é claríssimo: na estimação com efeitos fixo continentais, os resultados são convergentes com as evidências apresentadas no capítulo 4 . Os efeitos heterogêneos da democracia variam da forma esperada: efeitos positivos da democracia entre os países mais desiguais e efeitos negativos entre os países mais desiguais, sendo o ponto de maior contundência negativa dos efeitos da democracia encontrado justamente entre o $8^{\circ}$ e $9^{\circ}$ decil. Retornando nossa atenção à Figura 4, a estimação de SIID com efeitos fixos continentais é entre as três apresentadas a que mais se aproxima dos achados anteriores.

Já em ambas as especificações com efeitos fixos regionais (com efeitos fixos temporais ou não), o formato da curva de efeitos heterogêneos estimada com os dados de EHII apenas para os casos onde a informação de SIID não é faltante se

\footnotetext{
113 Contando com a perda de casos por dados faltantes nas variáveis controles, a estimação com SIID usa ao todo 2101 países-anos para estimar os efeitos da democracia, enquanto os modelos com EHII utilizam-se de 3781 casos e os modelos que serão analisados a seguir com os dados de SWIID possuem 4267 países-anos.
} 
aproxima muito das duas curvas da própria Figura 4, indicando que democracia teria um efeito homogêneo e nulo sobre desigualdade. Posto isto, podemos concluir que os efeitos distintos encontrados na Figura 4 decorrem de uma questão predominantemente amostral do que das próprias discrepâncias metodológicas entre as técnicas de padronização dos dados de GINI. Isto coloca em destaque a importância da ampliação do escopo geográfico dos bancos de dados sobre desigualdade e da necessidade de incorporação de informações a respeito da dinâmica da evolução da desigualdade econômica nos países em desenvolvimento para a realização de uma análise mais acurada do fenômeno. $\mathrm{O}$ foco excessivo nas economias mais desenvolvidas tem um enorme potencial em enviesar a análise empírica.

Prosseguindo à verificação da robustez dos achados sobre os efeitos heterogêneos da democracia sobre a desigualdade econômica, na Figura 5 apresentamos a estimação desses efeitos a partir dos dados de GINI sobre a desigualdade econômica bruta do SWIID, que inclusive é mais abrangente que o próprio projeto da UTIP-EHII. O mesmo método de identificação foi utilizado. Nenhum instrumento identificou corretamente as especificações com efeito fixo regional. A especificação sem efeito fixo é identificada apenas por difusão regional, a especificação com efeito fixo continental é identificada por difusão regional e continental, enquanto as duas especificações com efeitos fixos temporais - efeitos fixos continentais ou regionais - são identificadas por difusão regional e mundial. 
Sem Efeito Fixo

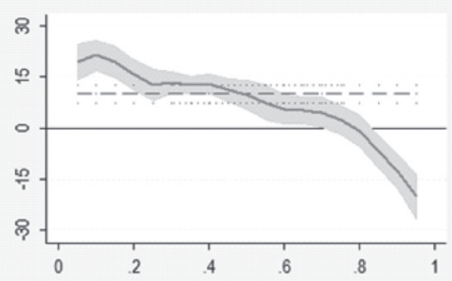

Efeitos Fixos Regionais e Temporais

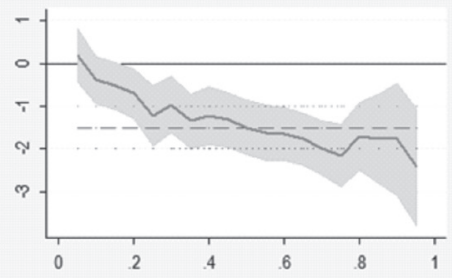

Efeitos Fixos Continentais

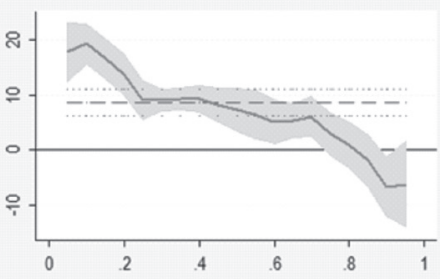

Efeitos Fixos Continentais e Temporais

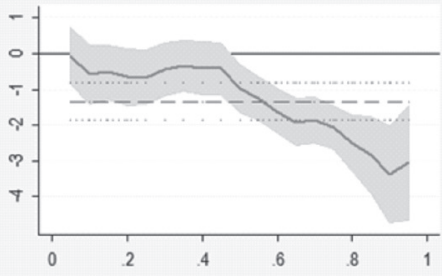

Figura 5 - Efeitos heterogêneos da democracia sobre a desigualdade econômica - Standardized World Income Inequality Data (SWIID) para renda bruta ${ }^{114}$ Fonte: CGV e SWIID

Como podemos observar na Figura 5, os formatos das curvas sobre os efeitos heterogêneos da democracia sobre a desigualdade permanecem bastante semelhantes aos resultados encontrados no capítulo anterior. Os efeitos positivos da democracia sobre a desigualdade são mais fortes no início (esquerda) da distribuição de desigualdade e os efeitos são abrandados com o movimento crescente no eixo horizontal da distribuição de desigualdade. O que se destaca nas curvas da

${ }^{114} \mathrm{O}$ modelo sem efeito fixo é identificado apenas por difusão regional. Já a especificação com efeito fixo continental é identificada por difregiao e difcont e as duas especificações com efeitos fixos temporais são identificadas por difmundo e difregião. 
metade superior do gráfico, que não apresentam efeitos fixos ou só incluem efeitos fixos continentais, é o desaparecimento dos efeitos positivos homogêneos no início da distribuição. Há uma clara matização monotônica dos efeitos positivos da desigualdade do $1^{\circ}$ decil da distribuição até que no $8^{\circ}$ decil se tornam negativos ao cruzar o limiar dos efeitos nulos. Já os gráficos da metade inferior da figura indicam que os efeitos da democracia sobre a desigualdade nunca são positivos. São nulos no início da distribuição e tornam-se gradativamente mais negativos com o avanço no eixo horizontal em direção à direita da distribuição de desigualdade. E nos quatro gráficos os efeitos negativos mais contundentes da democracia sobre a desigualdade encontram-se no final da distribuição, isto é no decil dos países-anos mais desiguais da amostra.

Mais uma vez fica evidente que a estimação dos efeitos médios da democracia sobre a desigualdade a partir do suposto de sua homogeneidade é equivocada e inconsistente. Enquanto na estimação sem efeitos fixos e com efeitos fixo continentais os resultados são significantes e positivos, na estimação com efeitos fixos regionais e temporais e com efeitos fixos continentais e temporais os resultados são sempre negativos e significantes. Estes resultados estão representados pela linha tracejada horizontal.

Resultados bastante semelhantes aos apresentados na Figura 5 são obtidos se estimarmos os efeitos da democracia sobre a desigualdade a partir da desigualdade de renda líquida do SWIID. A especificação sem efeitos fixos tem o mesmo formato, com a única diferença que a amplitude dos efeitos é menor, variando entre +10 no início da distribuição e -10 no final. O mesmo padrão também se repete na especificação com efeitos fixos continentais, com exceção do fato que os efeitos 
tornam-se negativos no $6^{\circ}$ decil e não no $8^{\circ}$. Por fim, as curvas da metade inferior da figura são também semelhantes, com exceção apenas do fato que elas recuperam o formato tradicional, no qual os efeitos são positivos no início da distribuição, tornamse negativos entre o $2^{\circ}$ e o $4^{\circ}$ decil e os efeitos mais negativos e contundentes são encontrados no $9^{\circ}$ decil.

Posto isto, podemos concluir que a principal diferença encontrada entre os modelos que analisam o efeito da democracia sobre a desigualdade econômica mensurada pela renda líquida do efeito da democracia sobre a desigualdade de renda bruta é apenas uma questão de magnitude desses efeitos, que são um pouco menores no primeiro. Tal resultado é esperado uma vez que a desigualdade da renda líquida tende a ser menor do que a desigualdade por renda bruta, caso os países adotem um sistema tributário minimamente regressivo.

Fora isso, ao compararmos os resultados das estimações com diferentes tipos de renda, vemos que os formatos são razoavelmente semelhantes, apontando mais uma vez que a diferenciação que a literatura faz sobre estes dois tipos de desigualdade não é convincente teórico e empiricamente. Isto porque, tal como posto por Bergh (2005), os sistemas de taxação e transferência e as políticas públicas redistributivas têm efeito tanto sobre a renda líquida do presente quanto sobre a oferta de trabalho no futuro, impactando, portanto, nos formatos das distribuições líquida e bruta dos ganhos.

Finalmente, na Figura 6 apresentamos os gráficos dos efeitos heterogêneos da democracia sobre a distribuição dos recursos entre o capital e trabalho, variável com a qual Houle (2009) analisa a relação entre democracia e desigualdade. Os resultados são bastante diferentes dos encontrados no restante da pesquisa, o que parece indicar o fato que a fração do valor 
agregado pertencente ao capital não é uma boa proxy para medir a desigualdade econômica entre os indivíduos. A primeira constatação que merece ser destacada é que independente do quantil analisado, o efeito da democracia sobre a fração do PIB pertencente ao capital é negativa. Isto é, a democracia sempre e de forma homogênea aumenta a participação do trabalho no processo de agregação de valor. Podemos concluir que esse efeito é homogêneo, uma vez que boa parte das curvas de efeitos heterogêneos está contida dentro do intervalo de confiança da curva de efeito médio.

Destarte, no que se refere à análise da relação entre democracia e a participação do capital na agregação do valor, podemos realmente assumir a hipótese de que seus efeitos são homogêneos e, portanto, independente do contexto socioeconômico no qual a competição política ocorre. Além do mais, é importante ter em mente que independentemente da quantidade de recursos pertencentes ao trabalho ou ao capital, isto não quer dizer diretamente que estes recursos são distribuídos concentrada ou homogeneamente entre os trabalhadores e, consequentemente, os países nos quais o valor agregado é mais concentrado no trabalho (lado esquerdo dos gráficos) ou no capital (lado direito) não necessariamente possuem maior ou menor desigualdade econômica.

Fica claro, por outro lado, que a democracia impacta positivamente a participação do trabalho no valor adicionado de uma dada economia, mas este impacto não é condicionado em relação ao nível de concentração da renda no capital. Enquanto nas análises feitas pelas diferentes mensurações do GINI, fica evidente que quanto maior for a desigualdade de renda entre os indivíduos, maior será o efeito da democracia na sua redução. Conectando os dois resultados e assumindo o 
pressuposto que o capital é concentrado na mão de alguns indivíduos, que conformariam a elite econômica, podemos concluir que a democracia reduz a desigualdade nas sociedades mais desiguais, mas isto não afeta a fração do valor adicionado que está concentrado no capital, além do impacto geral que a democracia tem em proteger o papel do trabalho no processo de agregação de valor.

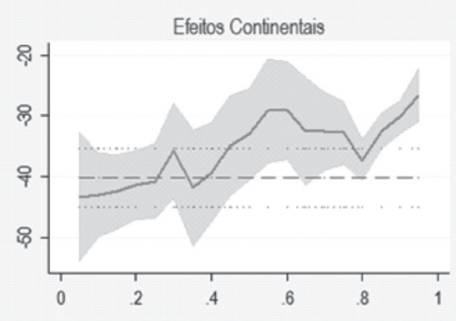

Efeitos Regionais

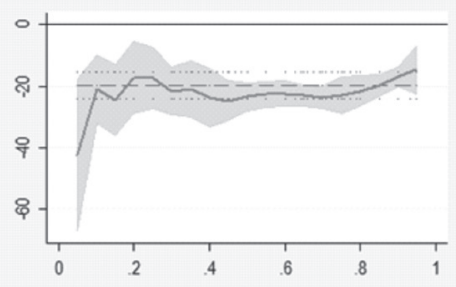

Efeitos Continentais e Temporais

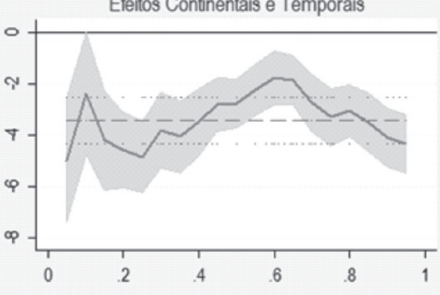

Efeitos Regionais e Temporais

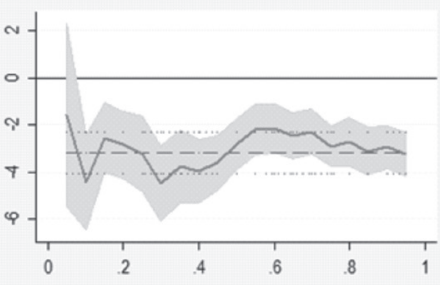

Figura 6 - Efeitos heterogêneos da democracia sobre a participação do capital na agregação de valor ${ }^{115}$ Fonte: CGV e Houle (2009)

115 Não identificamos adequadamente democracia na especificação sem nenhum efeito fixo e só conseguimos aceitar a hipótese de restrição de exclusão da especificação com efeitos fixos regionais e temporais a $5 \%$ de significância. A especificação com efeito fixo continental foi identificada por difcont e difregião; já a especificação com efeito fixo continental e temporal foi identificada por difmundo e difcont; a especificação com efeito fixo regional foi identificada por difmundo e llong; e, finalmente, a especificação com efeito fixo regional e temporal é identificada por difmundo, difcont e llong. 


\subsection{Desigualdade e democracia desde 0 século XIX}

Até agora os achados da relação entre democracia e desigualdade indicam que de fato os efeitos da democracia sobre a desigualdade são heterogêneos e o impacto da democracia em direção à redução das disparidades econômicas entre os indivíduos é maior nos países mais desiguais. Contudo os achados refletem apenas o que aconteceu na segunda metade do século XX. Diante disso nos questionamos se estes resultados permanecem se observamos a relação entre as duas variáveis em um horizonte histórico mais abrangente e que incorpore os processos de democratização dos primeiros regimes representativos democráticos da Europa Ocidental, América do Norte e Oceania.

Para responder a tal questionamento, iremos analisar a relação entre democracia e desigualdade em um intervalo histórico de longa duração. Com os dados já apresentados de Bourguignon e Morrison (2002) e trabalhados por Ansell e Samuels (2014), temos um banco alternativo que permite capturar os efeitos da democracia e desigualdade nesta escala histórica maior. Obviamente que a escala mais extensa dos dados não resolve o problema da relação causal inversa entre democracia e desigualdade. E para tal adotamos a mesma metodologia e os mesmos tipos de instrumentos de difusão de democracia e de posicionamento longitudinal do país para identificar a relação.

O cálculo da difusão de democracia é refeito a partir da nova mensuração de democracia que associa aditivamente três regras distintas: a) os regimes definidos como democráticos por Boix e Rosato (2001), b) os regimes políticos que ampliaram o direito de voto a $100 \%$ da população masculina adulta (PRZEWORSKI, 2009) e c) os regimes que proíbem a existência legal da escravidão em seu território. 
Uma restrição empírica que adotamos nessa subseção é a não inclusão de efeitos fixos regionais. Conforme já exposto no capítulo 3, os autores dos dados de desigualdade Bourguignon e Morrison (2002) calcularam os dados de mais de 70\% dos anos-países disponíveis na amostra a partir da estrutura econômica regional e não nacional. Dos 53 países para os quais temos informações sobre desigualdade e regime político, apenas para 16 temos os dados de desigualdade calculados a partir da própria unidade econômica nacional. Desta forma, a inclusão de efeitos regionais retira boa parte da variabilidade dos dados, enviesando a análise. E, consequentemente, não teríamos poder estatístico para discernir se os resultados obtidos seriam decorrentes da própria dinâmica dos dados ou do nível de agregação a partir do qual os cálculos dos GINIs de Bourguignon e Morrison (2002) foram feitos.

Além das novas medidas de desigualdade, democracia e difusão de democracia, também incluímos novos vetores de variáveis controles. Isto porque o conjunto de controles utilizados nas especificações anteriores também foi compilado apenas para a $2^{\text {a }}$ metade do século XX. Na nova especificação incluímos as seguintes três variáveis de controle: o PIB real per capita como medida do nível de desenvolvimento econômico, o nível de escolaridade da população e a desigualdade da distribuição da propriedade rural, além disso, incluímos também variáveis de tendência. Utilizamos a medida de renda per capita de Angus Maddison (1997) e as medidas de desigualdade rural e de níveis de escolaridade de Tatu Vanhanen $(2000)^{116}$.

\footnotetext{
116 A medida de desigualdade rural é calculada por Ansell e Samuels a partir das medidas de agricultura familiar (Family farms) e do nível de urbanização da população, ambas de Tatu Vanhanen (2000). A desigualdade rural é obtida a partir da operação: (1 - agricultura familiar $)^{*}(1$ - população urbana $)$ - a proporção da
} 
Empregamos para as três variáveis as mesmas transformações e os dados utilizados por Ansell e Samuels (2014) ${ }^{117}$. Na Tabela 14 apresentamos a estatística de cada uma delas.

Tabela 14 - Estatística descritiva das variáveis de controle

\begin{tabular}{|c|c|c|c|c|c|c|}
\hline Variáveis & Indicador & $\mathbf{N}$ & Média & Mediana & $\begin{array}{l}\text { Des. } \\
\text { Pad }\end{array}$ & Fonte \\
\hline $\begin{array}{l}\text { Desenvol- } \\
\text { vimento } \\
\text { Econômico }\end{array}$ & $\begin{array}{c}\mathrm{Ln}\{\mathrm{PIB} \text { real } \\
\text { per capita } \text { cat }\}\end{array}$ & 10354 & 7.70 & 7.62 & 0.91 & Maddison \\
\hline $\begin{array}{l}\text { Desigualdade } \\
\text { Rural }\end{array}$ & $\begin{array}{c}(1-a g r . f) * \\
(1-\text { popurb })\end{array}$ & 9612 & 50.73 & 52.25 & 24.72 & Vanhanen \\
\hline Escolarização & $\begin{array}{c}1 / 2 * \text { (alfabetização }+ \\
n^{0} \text { estudantes) }\end{array}$ & 9613 & 32.81 & 30.25 & 23.11 & Vanhanen \\
\hline
\end{tabular}

Na especificação final das variáveis controles incluímos um termo quadrático para o desenvolvimento econômico, tal como fizemos nos modelos anteriores, e uma linha de tendência de ordem 3. Incluímos também uma variável dummy identificando o período entre o começo e o final das duas Grandes Guerras Mundiais que, conforme vimos no capítulo 3, é caracterizado por uma forte queda da desigualdade econômica. Além disso, como o horizonte temporal desta análise é maior, optamos por defasar democracia em três anos e difusão de democracia em seis. Desta forma, as equações estimadas são:

concentração fundiária, ponderado pelo peso rural da população. Já a medida de escolaridade é a média da porcentagem de adultos alfabetizados e do número de estudantes por habitante (ANSELL; SAMUELS, 2014).

117 Agradecemos mais uma vez a gentileza dos professores Ben Ansell e David Samuels, por terem nos fornecido todos os dados utilizados na análise histórica da relação entre democracia e desigualdade. 


\title{
1) EQUAÇÃO ESTIMADA NO PRIMEIRO PASSO:
}

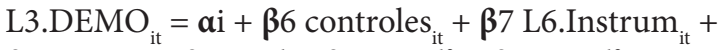 \\ $\boldsymbol{\beta} 8$ contin. $+\boldsymbol{\beta} 9$ tend $+\boldsymbol{\beta} 10$ tend $^{2}+\boldsymbol{\beta} 11$ tend $^{3+} \boldsymbol{\pi}_{\mathrm{it}}$
}

\section{2) EQUAÇÃO ESTIMADA NO SEGUNDO PASSO:}

Assumindo especificação linear para o $\tau$ - ésimo quantil:

$Q_{\tau}[. \mid X=x]=\boldsymbol{\alpha i}+\boldsymbol{\beta} 1$ controles $_{\mathrm{it}}+\boldsymbol{\beta} 2$ L3. DEMO $_{\mathrm{it}}+$

$\beta 3$ contin. $+\boldsymbol{\beta} 4$ tend $+\boldsymbol{\beta} 5$ tend $^{2}+\boldsymbol{\beta} 5$ tend $^{3}+\boldsymbol{\varepsilon}_{\mathrm{it}}$

No qual $Q_{\tau}[. \mid \mathbf{X}=\mathrm{x}] \equiv \frac{\text { inf }}{\boldsymbol{q}} \boldsymbol{P}(. \leq \mathbf{q} \mid \mathbf{X}=\mathrm{x}) \geq \tau$ sendo $o$ $\tau$-ésimo quantil condicionado na distribuição da variável dependente BM-GINI.

Em relação à estratégia de identificação de democracia, não temos variáveis instrumentais que nos permitam identificar adequadamente a especificação sem a presença de algum efeito fixo. Isto porque embora as variáveis de difregião e difcont estejam relacionadas fortemente com democracia, ambas violam os testes de Wald da hipótese de restrição de exclusão. Já nas especificações de efeitos fixos continentais e de efeitos fixos continentais e temporais, estas mesmas duas variáveis identificam democracia e não estão relacionadas com desigualdade, qualificando-se, portanto, como instrumentos adequados.

O Gráfico 18 apresenta a relação entre democracia e desigualdade na especificação com efeitos fixos continentais. Mais uma vez, fica claro que os efeitos da democracia sobre a desigualdade são fundamentalmente heterogêneos e o suposto sobre a homogeneidade dos efeitos é equivocado, mesmo quando analisamos um dado sobre GINI de maior escala histórica 
abrangendo os processos de democratização da América do Norte, Oceania e Europa Ocidental. O Gráfico 18 não deixa dúvidas de que modelos lineares condicionais à média (MQO) - a reta horizontal tracejada - refletem de maneira assaz inadequada e reduzem em muito a complexidade existente na relação entre democracia e desigualdade.

Os efeitos da democracia só se tornam negativos no final da distribuição, mais especificamente nos $30 \%$ países-anos mais desiguais da amostra, justamente os países-anos nos quais é maior a probabilidade do surgimento de uma demanda por redistribuição no seio da cidadania e onde o cálculo pelos partidos do custo benefício da adoção de plataforma eleitoral e políticas públicas que foquem nesse problema tende a ser positivo. Por outro lado, no primeiro decil (onde estão os países-anos mais iguais da amostra) existe um forte efeito positivo da democracia, em torno de 10 pontos de GINI, mas que é decrescente até o $2^{\circ}$ decil, onde os efeitos positivos se estabilizam em torno de 7 pontos. A partir do $5^{\circ}$ decil, os efeitos voltam a ser amenizados e no $7^{\circ}$ decil essa gradativa suavização cruza o valor zero (a linha referencial do efeito nulo) e seus efeitos tornam-se negativos.

Resumindo, a democracia aumenta a desigualdade de maneira substancial entre os países-anos mais iguais e após certo nível de desigualdade seus efeitos positivos são arrefecidos monotonicamente. Nos países-anos mais desiguais da amostra, os seus efeitos são verdadeiramente negativos, sendo que o ápice deste efeito negativo está no $9^{\circ}$ decil, por volta de -6 pontos de GINI. E a estabilização positiva dos efeitos da democracia sobre a desigualdade não acontece nos países-anos mais igualitários, mas sim numa região mais intermediária do gráfico, entre o $2^{\circ}$ e o $5^{\circ}$ decil da distribuição de desigualdade entre os países. 


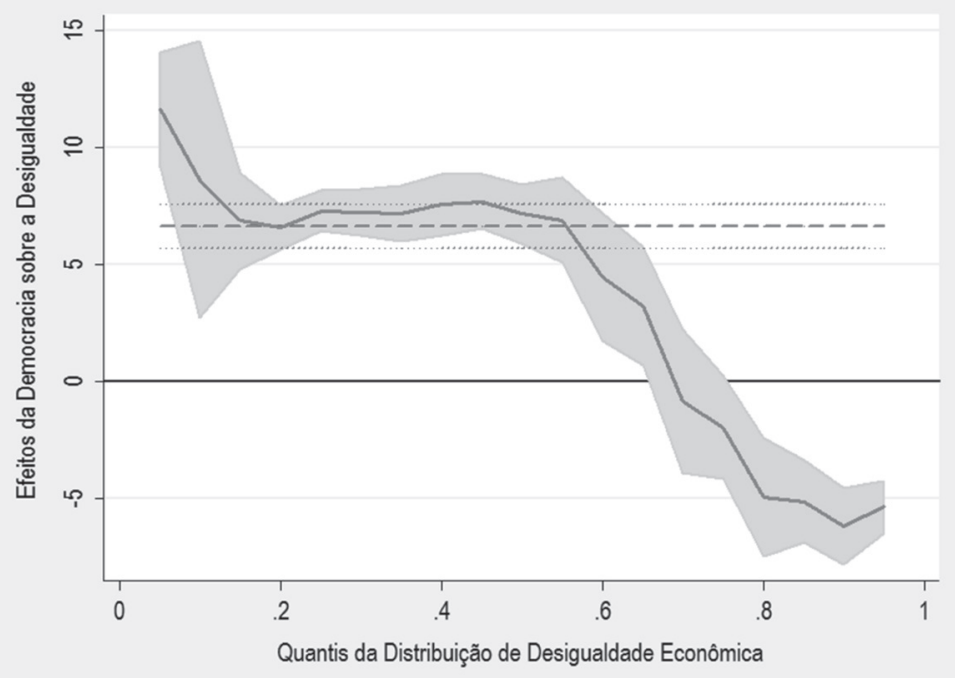

Gráfico 18 - Efeitos heterogêneos da democracia sobre a desigualdade econômica - efeitos fixos continentais Fonte: BOIX, ROSATO e BM-GINI

No Gráfico 19 repetimos a mesma estimação, mas agora usando como especificação efeitos fixos continentais e efeitos temporais para o controle de choques exógenos por meio de dummies de década. O vetor de variáveis controles e os instrumentos de identificação são os mesmos. O gráfico corrobora o resultado anterior, demonstrando que mesmo com a adição destas dummies de décadas, os efeitos da democracia sobre a desigualdade são fundamentalmente heterogêneos e a abordagem tradicional que assume efeitos homogêneos é equivocada. Ademais, o formato do gráfico é essencialmente o mesmo. Os efeitos negativos da democracia sobre a desigualdade surgem a partir do $7^{\circ}$ decil da distribuição, quando a curva de efeitos heterogêneos cruza a linha de referência do efeito nulo 
e o ápice dos efeitos negativos está no $9^{\circ}$ decil, em torno de -5.5 pontos de GINI.

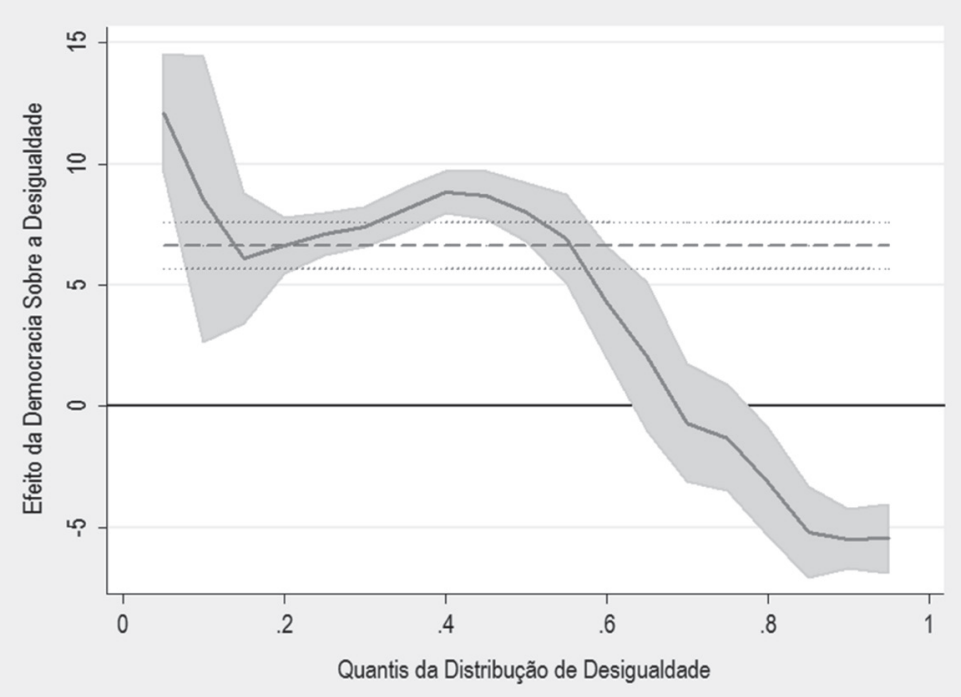

Gráfico 19 - Efeitos heterogêneos da democracia sobre a desigualdade econômica - efeitos fixos continentais e temporais (décadas) Fonte: BOIX, ROSATO e BM-GINI

No Gráfico 20 adicionamos à especificação anterior efeitos temporais com dummies de ano, o que torna a estimação mais exigente. Os vetores de variáveis controles e instrumentos permanecem idênticos. E mais uma vez o gráfico corrobora os resultados encontrados ao longo de toda a pesquisa, os efeitos da democracia sobre a desigualdade são fundamentalmente heterogêneos e a abordagem tradicional que assume efeitos homogêneos é equivocada. Ademais, o formato do gráfico é essencialmente o mesmo dos formatos encontrados nos Gráficos 18 e 19. Os efeitos negativos da democracia sobre a desigualdade surgem a partir do $7^{\circ}$ decil da distribuição, quando 
a curva de efeitos heterogêneos cruza a linha de referência do efeito nulo e o ápice dos efeitos negativos está no $9^{\circ}$ decil, em torno de -5.4 pontos de GINI.

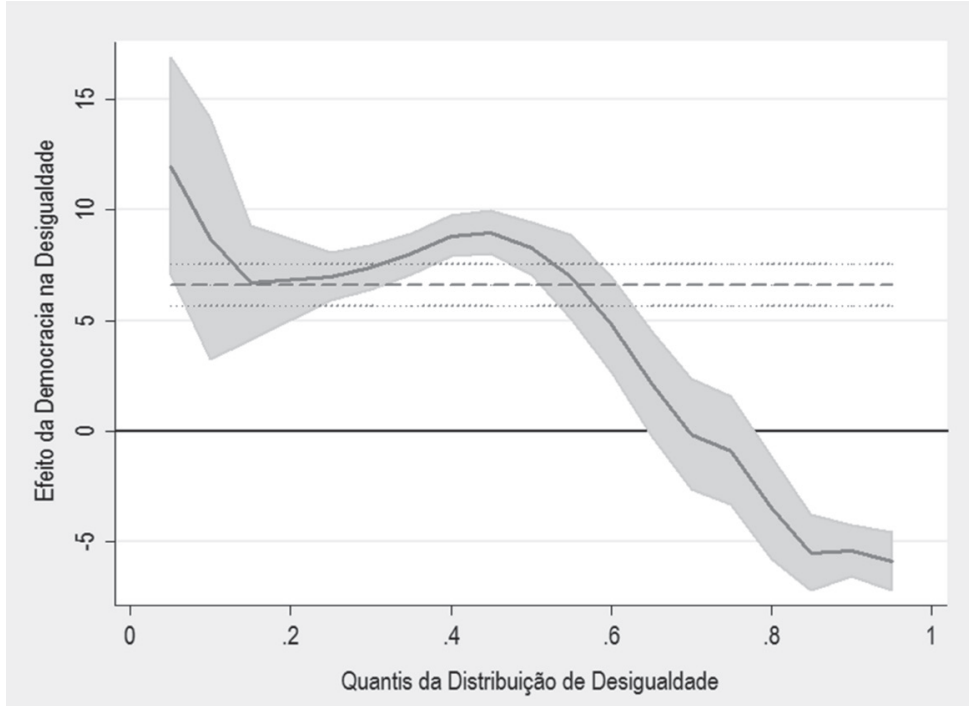

Gráfico 20 - Efeitos heterogêneos da democracia sobre a desigualdade econômica - efeitos fixos continentais e temporais (anos) Fonte: BOIX, ROSATO e BM-GINI

Outro problema de pesquisa apresentado na seção 4.2 no capítulo 4 foi a questão da existência de muitas observações faltantes nos dados de desigualdade econômica. A solução apresentada foi a utilização de intervalos temporais maiores como unidade de análise, estratégia muito utilizada na literatura sobre desigualdade. Repetimos mais uma vez essa abordagem e re-estimamos a relação entre democracia e desigualdade tendo com unidade de análise o país-década. Com esta alteração temos um novo banco de dados, agora com 53 países e 10 unidades temporais. 
Nos Gráficos 21 e 22 apresentamos estes resultados. No primeiro incluímos na especificação apenas efeitos fixos continentais e no segundo efeitos fixos continentais e dummies de décadas. Como método de identificação utilizamos as mesmas regras anteriores e identificamos democracia com as variáveis de difusão regional e continental. Uma alteração na especificação foi a não inclusão de defasagens para mensurar a variável independente de democracia e a inclusão de apenas uma defasagem para mensurar os instrumentos de difusão. A escolha por não utilizarmos tantas defasagens como na estimação anterior decorre de duas ponderações: a própria extensão da unidade temporal abrangendo um longo período de 10 anos e o fato de termos poucas unidades de tempo na análise.

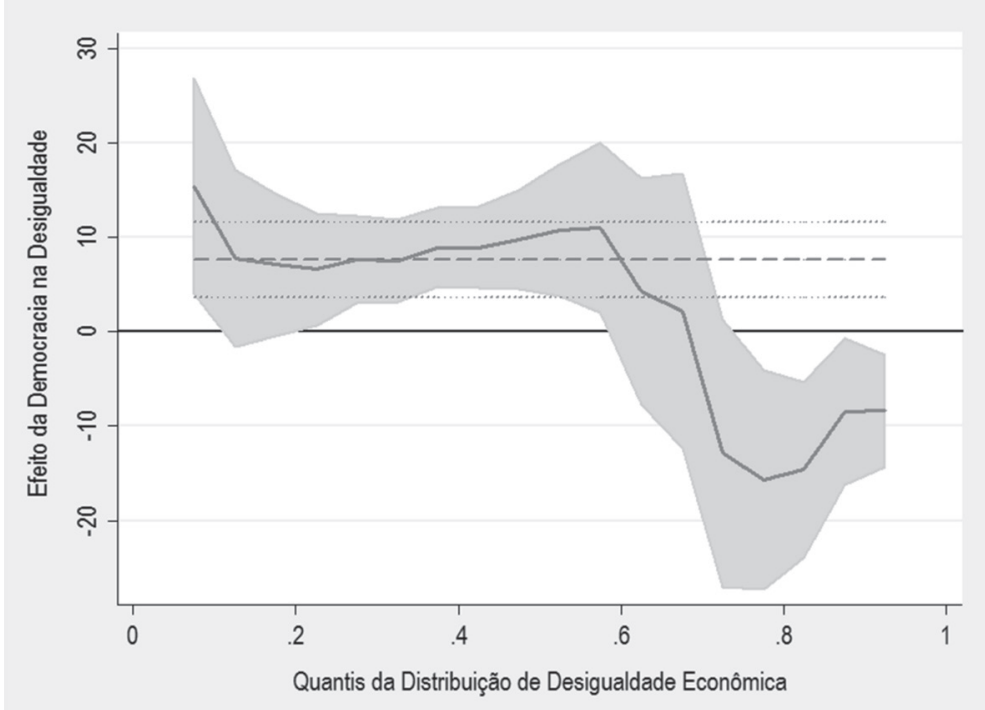

Gráfico 21 - Efeitos heterogêneos da democracia sobre a desigualdade econômica - efeitos fixos continentais - países-décadas Fonte: BOIX, ROSATO e BM-GINI 
No Gráfico 21 encontramos um formato dos efeitos heterogêneos bastante semelhante com aquele encontrado na primeira especificação apresentada no Gráfico 1 (p. 197). Existem, basicamente, três momentos distintos dos efeitos da democracia sobre a desigualdade. Um longo e homogêneo efeito positivo ao longo da primeira metade da distribuição, com um efeito positivo de ser democracia ao longo dos 10 anos de cerca de 10 a 11 pontos de GINI. Após o $5^{\circ}$ decil (ou a mediana), uma constante e monotônica amenização dos efeitos positivos da democracia sobre a desigualdade, até que um pouco antes do $7^{\circ}$ decil a curva de efeitos heterogêneos cruza a linha de referência dos efeitos nulos e a democracia passa a ter um efeito redutor da desigualdade. No $8^{\circ}$ decil esse efeito negativo atinge seu valor máximo, em torno de -15 pontos de GINI.

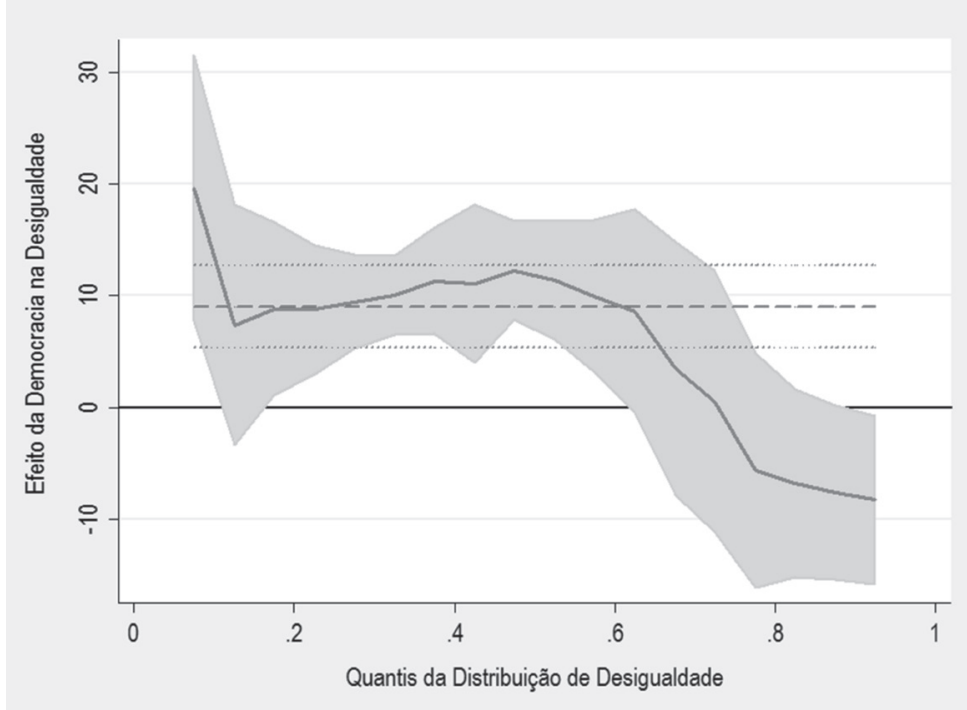

Gráfico 22 - Efeitos heterogêneos da democracia sobre a desigualdade econômica - efeitos fixos continentais e temporais - países-décadas Fonte: BOIX, ROSATO e BM-GINI 
No Gráfico 22 adicionamos à especificação anterior efeitos temporais com dummies de década. $\mathrm{E}$ as mesmas conclusões podem ser retiradas com a análise do Gráfico 22 , com exceção apenas de o fato de que o maior efeito negativo da desigualdade não se encontra no $8^{\circ}$ decil, mas sim na ponta da distribuição, onde os efeitos atingem por volta de -8 pontos de GINI. Permanece, portanto, a constatação que existe um efeito positivo da democracia que é relativamente constante ao longo dos primeiros cinco decis da distribuição, ainda que nos primeiros centis estimados (o $7^{\circ}$ e $8^{\circ}$ centil) os efeitos sejam muito mais fortes (cerca de 17 pontos de GINI), mas a seguir reduzidos para apenas 9 pontos de GINI no $1^{\circ}$ decil, a partir do qual são mantidos relativamente dentro de um mesmo intervalo. E após os níveis intermediários de desigualdade, a democracia passa a ter seus efeitos positivos amenizados, até que estes se tornam negativos e atingem o valor negativo máximo no final da distribuição.

Posto isto, podemos retomar as três principais constatações que fizemos sobre a democracia com um vasto leque adicional de evidências empíricas que as respaldam: a saber: 1) a relação entre democracia e desigualdade não deve ser tratada como homogênea e nem seus efeitos são monotônicos ao longo da distribuição da desigualdade; 2) existe uma relativa homogeneidade dos efeitos da democracia no início da distribuição de desigualdade e só apenas quando um país/ década atinge níveis intermediários de desigualdade é que a democracia passa a ter seus efeitos positivos amenizados; e, por fim, 3) apenas no final da distribuição de desigualdade que a democracia age de maneira mais contundente na redução da desigualdade, o que parece indicar um limiar básico a partir do qual a competição política democrática passa a ter como tema principal a efetiva redução da desigualdade econômica. 


\subsection{Persistência democrática e a desigualdade}

Como último exercício empírico verificamos se os efeitos do acúmulo da experiência democrática afetam os padrões da relação entre democracia e desigualdade encontrados ao longo da pesquisa. Muller (1988), inclusive, propôs e encontrou evidências sobre o argumento de que a democracia tem um efeito acumulado sobre a desigualdade e não em nível. Além disso, no capítulo 3 também encontramos evidências na curva de EHII do Gráfico 10 - de que os efeitos negativos da democracia sobre a desigualdade tomavam corpo somente a partir da segunda década democrática, o que pode ser indício de que os efeitos não são imediatos, mas sim resultados do acúmulo e aprendizado de práticas e experiência da competição política democrática.

Para verificar esta pequena modificação na hipótese, utilizamos o mesmo desenho de pesquisa, incluindo as mesmas variáveis instrumentais. Isto porque é possível defender o argumento que a difusão da democracia não só aumenta a probabilidade de um país tornar-se democrático, como também aumenta a probabilidade deste mesmo país continuar sendo governado sob um governo democrático. Do ponto de vista formal, os instrumentos passam nos testes necessários, atendendo aos dois critérios de validade da estimação por variável instrumental.

Mensuramos a persistência democrática a partir da contagem de anos que um país permanece ao longo do tempo em um regime democrático. Mas como é possível que os efeitos da democracia sejam decrescentes no tempo - e também para reduzir o peso na estimação dos casos de alguns poucos países cuja experiência democrática é de longa duração - optamos 
por uma transformação logarítmica desta contagem ${ }^{118}$. Testamos a relação nas especificações com efeitos fixos continentais e efeitos fixos temporais nos dados do CGV e EHII e nos dados da análise de longo prazo feita com o BM-GINI. Os resultados são apresentados na Figura 7. Na metade superior estão os gráficos do banco de dados mais recente e na metade inferior os gráficos cujas variáveis mensuram a relação de longo prazo entre democracia e desigualdade.
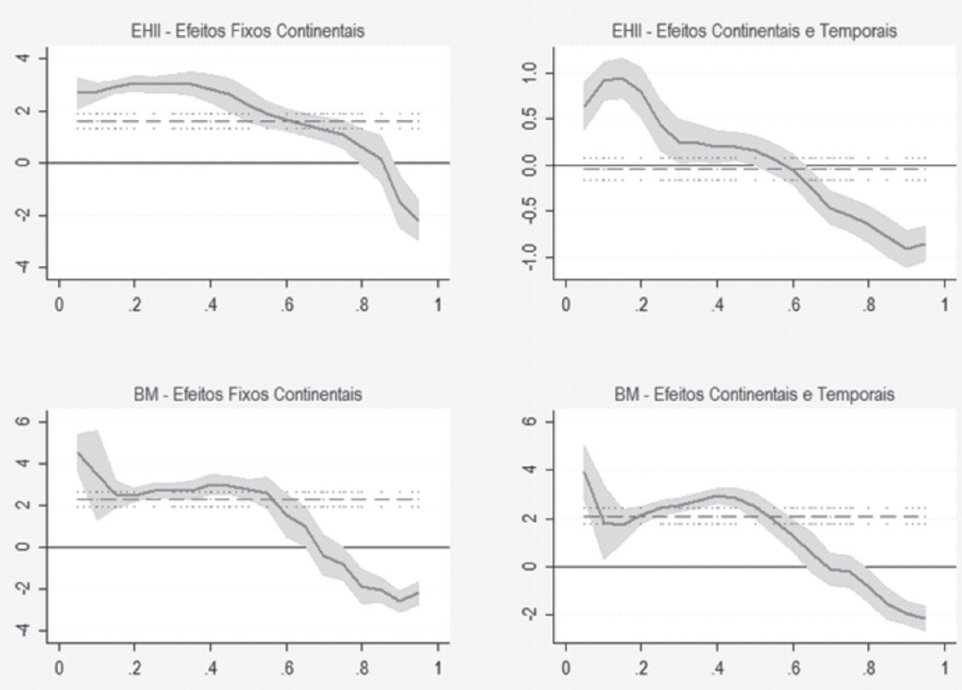

Figura 7 - Efeitos heterogêneos da persistência democrática sobre a desigualdade econômica ${ }^{119}$ Fonte: CGV e UTIP-EHII, BOIX-ROSATO e BM-GINI

118 Calculamos a variável persistência democrática segundo a seguinte fórmula: persistência $=\log \left(n^{\circ}\right.$ de $\operatorname{anos}$ democráticos +1$)$. A opção pela adição de 1 decorre do fato de que uma ditadura recebe um valor de 0 de número de anos democráticos e não existe uma transformação logarítmica para esse valor. A variável tem média de 0.64 e desvio padrão de 1.29 .

119 Os modelos que mensuram os efeitos heterogêneos da persistência democrática mensurada pelo CGV sobre o EHII são instrumentados por difcont difregiao e horiental llong na especificação com efeitos fixos continentais e por 
Mais uma vez os resultados estão de acordo com as propostas teóricas do Capítulo 2, não importando o fato de estarmos medindo a democracia em seu tempo presente ou como o acúmulo da experiência democrática. Nos quatro gráficos encontramos, novamente, fortes evidências de que os efeitos da democracia são heterogêneos ao longo do eixo de desigualdade e são negativos entre os países-anos mais desiguais.

Entre os países-anos mais iguais, justamente aqueles onde não deve existir uma demanda por redistribuição pela cidadania, a competição política democrática tem como efeito principal o aumento da desigualdade econômica. Isto é, a livre e aberta competição entre governo e oposição estimula a adoção de políticas que, em comparação às ditaduras, produzem mais desigualdade econômica, já controlando para os efeitos que diferentes níveis de desenvolvimento ou mesmo o papel da economia de mercado sobre a desigualdade. Em relação a esta consistente evidência do estudo, não temos um argumento teórico explicativo que o justifique, além da mera conjuntura de que este resultado é guiado empiricamente pelos eventos ocorridos nos países que saíram da esfera comunista. Isto porque, enquanto os regimes comunistas produziram os níveis mais baixos de desigualdade econômica, após a transição democrática foram sacudidos por movimentos políticos

difmundo e difcont na especificação com efeitos fixos continentais e temporais. Os modelos que mensuram os efeitos heterogêneos da persistência democrática mensurada pela medida modificada de Boix e Rosato sobre o BM-GINI são instrumentados por difcont e difregião no modelo só com efeitos fixos continentais e por difmundo, difcont e difregião no modelo com efeitos fixos continentais e dummies de décadas. Nas quatro especificações os instrumentos atendem aos dois critérios de validade da estimação por variável instrumental. 
e econômicos que tiveram como principal consequência um vigoroso aumento da desigualdade ${ }^{120}$.

Por outro lado, o resultado mais uma vez indica de maneira categórica a veracidade empírica da hipótese sobre os efeitos heterogêneos da democracia e que este regime político de fato reduz a desigualdade nas sociedades mais desiguais. $\mathrm{E}$ a rationale deste resultado decorre do fato que com o aumento da desigualdade econômica, existe condições para o surgimento, ceteris paribus, de uma maior demanda por redistribuição econômica no seio da cidadania e um decorrente interesse dos partidos em responder efetivamente a esta demanda por meio de plataformas e políticas públicas que tenham como objetivo reduzir a desigualdade. Nos quatro gráficos da Figura 7 este resultado é encontrado, não importando desta forma o horizonte histórico da análise. Os efeitos mais agudos da democracia em direção à redução da desigualdade econômica estão definitivamente concentrados no final da distribuição. Em outras palavras, mesmo que os efeitos negativos estimados em cada uma das especificações variem, parece ser uma evidência incontestável que esses efeitos são mais agudos nos últimos decis da distribuição de desigualdade econômica.

\section{$\mathscr{8}$}

O objetivo principal deste capítulo foi aprofundar a consistência dos achados da relação entre democracia e de-

\footnotetext{
120 Por outro lado, verificamos a plausibilidade desta explicação com a introdução de uma variável dummy indicativa de o país ter sido membro ou não da zona de influência comunista. Os resultados positivos dos efeitos da democracia do início da distribuição são amenizados, mas permanecem significantes e positivamente relacionados com a desigualdade econômica nas quatro especificações da Figura 7. Desta forma, existem importantes questões a serem explicadas sobre este fenômeno e que devem ser foco de estudos mais aprofundados.
} 
sigualdade que é muito mais complexa e contextualizada às realidades socioeconômicas do que tal como foi trabalhada até agora pela literatura. Para tal desafio, analisamos esta relação utilizando outros dados de democracia e de desigualdade, outro tipo de mensuração de democracia e, ainda, outro banco de dados com uma abrangência histórica muito maior, mesmo tendo como custo uma reduzida dispersão geográfica. Em todas as seções o resultado foi categórico: a) os efeitos da democracia sobre a desigualdade são heterogêneos; b) em sociedades mais iguais a democracia produz desigualdade; e c) em sociedades mais desiguais a democracia a reduz de maneira contundente. Retomando as duas hipóteses apresentadas no capítulo 2, as conclusões permanecem consistentes após as mais diferentes análises realizadas.

H1: As democracias possuem em média um efeito negativo sobre a desigualdade.

H2: Os efeitos negativos da democracia sobre a desigualdade são maiores nas sociedades mais desiguais e tendem a ser menos relevantes em sociedades mais iguais.

Os dados apresentados respaldam de maneira inequívoca a Hipótese 2. Podemos afirmar que não nos resta dúvidas que os efeitos da democracia sobre a desigualdade econômica são heterogêneos e tendem a ser negativos nas sociedades mais desiguais. E nas sociedades iguais encontramos evidências robustas que os efeitos são positivos. Por outro lado, em relação à Hipótese 1, dada a existência destes efeitos heterogêneos da democracia, não está claro qual é o seu efeito médio sobre desigualdade. Ademais podemos diagnosticar, inclusive, diante dos achados desta pesquisa que as razões pelas quais a 
literatura tem encontrado enormes dificuldades em estimar um resultado sobre a relação entre a democracia e desigualdade que seja consistente com a utilização de modelos econométricos condicionais à média são decorrentes da própria existência destes efeitos heterogêneos.

Além disto, estes achados mostram que a estimação dos efeitos médios da democracia tem pouco significado prático ao reduzirem a complexidade do problema teórico da relação entre as duas variáveis, ignorando informações e interações que são fundamentais para uma verdadeira compreensão do problema. E, por fim, isto também explica porque no capítulo 3, no qual apresentamos a relação descritiva entre as duas variáveis, encontramos poucas diferenças entre as performances das ditaduras e das democracias sobre a desigualdade. Em todas as comparações feitas, tivemos como base a observação da evolução das médias de desigualdade entre democracias e ditaduras no tempo e no horizonte de democratização, o que é forte impedimento para a compreensão adequada de quais sejam os verdadeiros efeitos da democracia sobre a desigualdade econômica. 